\title{
LA VIDA DE LA INFANCIA EN LA CIUDAD Y SU CONFLICTO CON EL MUNDO ADULTO
}

The Life of Children in the City and its Conflict with the Adult World

\author{
Chema Segovia Collado \\ chema.segovia@gmail.com \\ Urbanista
}

RESUMEN: Este artículo plantea una revisión de la idea del derecho a la ciudad desde la perspectiva de la infancia. La argumentación parte de reconocer una situación de conflicto frente a los adultos que, por diferentes motivos incluso contradictorios, tiende a resolverse en perjuicio de la parte más débil. Tras un encuadre inicial, se reflexiona alrededor de cuatro problemas ante los que el derecho de los niños y las niñas a la ciudad se ve limitado: restricción del uso del espacio urbano, falta de autonomía excusada en la seguridad, crecimiento apartado de la vida en común y falta de participación en decisiones que les afectan. En el análisis de estos problemas, el texto intercala llamadas de atención y posibles cambios de enfoque. Como llamamiento a una mayor confianza y a una apertura comprometida, la reflexión se cierra reivindicando a la infancia como potencial elemento aglomerador de otros colectivos que, sin el suficiente reconocimiento, viven la ciudad en condiciones de desventaja.

Palabras clave: infancia, ciudad, inclusión, políticas urbanas.

ABSTRACT: This article reviews the right to the city from the child's perspective, based on the recognition of conflict between children and adults. For various and sometimes contradictory reasons, this conflict tends to prejudice the weaker party. The introductory framing is followed by reflections on four problems that affect children's right to the city: restrictions on their use of urban space, lack of autonomy under the guise of safety, growing up separated from community life, and no participation in matters that affect them. Alongside our analysis of these problems we identify areas for further attention and 
suggest alternative approaches. As an appeal for greater trust and commitment, the article ends with a call for childhood to be seen as having the potential to bring together other groups that, because they are under-recognised, have a disadvantaged experience of the city.

KeYWORDs: childhood, city, inclusion, urban politics.

RESUM: Aquest article planteja una revisió de la idea del dret a la ciutat des de la perspectiva de la infància. L'argumentació part de reconèixer una situació de conflicte cap als adults que, per diferents motius fins i tot contradictoris, tendeix a resoldre en perjudici de la part més feble. Després d'un enquadrament inicial, es reflexiona al voltant de quatre problemes davant els quals el dret dels nens i les nenes a la ciutat es veu limitat: restricció de l'ús de l'espai urbà, manca d'autonomia excusada en la seguretat, creixement apartat de la vida en comú i manca de participació en decisions que els afecten. En l'anàlisi d'aquests problemes, el text intercala tocs d'atenció i possibles canvis d'enfocament. Com a interpelació cap a una major confiança i cap a una obertura compromesa, la reflexió es tanca reivindicant a la infància com a potencial element aglomerador d'altres col-lectius que, sense el suficient reconeixement, viuen la ciutat en condicions de desavantatge.

Paraules Clau: infància, ciutat, inclusió, polítiques urbanes.

\section{Presentación. Pas a Pas, un camino de aprendizaje}

L a reflexión que este artículo plantea se nutre de diferentes lecturas y estudios, pero lo que verdaderamente la sostiene es la experiencia acumulada durante el itinerario de Pas a Pas, un proyecto de caminos escolares impulsado por el Ayuntamiento de Xàbia desde el curso 2014-2015.

Para hablar de Pas a Pas, lo más importante sería remarcar que el proyecto se ha esforzado desde el inicio por mantener una actitud inquieta. Gracias a eso ha desbordado el ámbito de la movilidad escolar para convertirse en un espacio de reflexión sobre los modos de vida actuales, la integración de la 
infancia en la ciudad y su papel en nuestra sociedad. La transversalidad de Pas a Pas fue reconocida en marzo de este año al resultar ganador de la «I Edición de los Premios Vivienda, Movilidad y Urbanismo con Perspectiva de Género» de la Generalitat Valenciana, dentro de la categoría de ciudades de más de 20000 habitantes.

El texto que sigue contiene muchos de los hallazgos que han hecho madurar a Pas a Pas y presenta las claves que actualmente orientan el proyecto. Es importante comenzar subrayando esa relación con la experiencia práctica porque el propósito de fondo de este artículo es reivindicar una reflexión profunda, exigente y constante en nuestras aproximaciones a la infancia desde las políticas urbanas.

Ahora que por fortuna cada vez son más los municipios que se deciden a poner en marcha proyectos centrados en la relación entre la infancia y la ciudad, desde nuestra experiencia queremos compartir la convicción de que una adecuada conceptualización del campo de trabajo y una buena carga de sentido crítico son vitales para dotar a estas iniciativas de la sensibilidad que exigen y para exprimir el enorme potencial que cobijan.

\section{Introducción. El derecho a la ciudad revisado desde la perspectiva de la infancia}

En los años recientes, la idea del «derecho a la ciudad» ha ganado una popularidad probablemente mayor al momento en que Henri Lefebvre (1969) la introdujo en el debate urbano. Se trata de una expresión poderosamente sugerente, alrededor de la cual se articulan numerosas denuncias de los impactos que el capitalismo genera sobre la vida cotidiana en las ciudades. Aún con eso, o precisamente por la recurrencia con la que se emplea, su significado específico resulta difuso, siendo la definición que con más frecuencia aparece la firmada por David Harvey (2012) que apunta que «el derecho a la ciudad es mucho más que el derecho a acceder a los recursos que la ciudad ofrece: es el derecho a cambiar y reinventar la ciudad de acuerdo a nuestros anhelos más profundos». De nuevo cargadas de fuerza y atractivo, estas palabras terminan siendo igualmente etéreas. A partir de ellas, cabría hacerse preguntas como: 
¿cambiar la ciudad de qué modo?, ¿quiénes?, ¿para quién?, ¿por qué vías?, ¿con qué poder?

Habría sido conveniente que una advertencia lanzada en el prefacio de Ciudades Rebeldes transcendiese tanto como la cita anterior. Ahí Harvey afirma que el derecho a la ciudad es un «significante vacío» que depende de quién lo esté dotando de sentido. En este caso, ese quién lo ocupan sus potenciales lectores, gente muy parecida a quien escribe y a quienes leéis: individuos con formación universitaria y un alto capital cultural, con una conciencia política más o menos formada e inclinada hacia la izquierda, con recursos relativos para participar en la transformación que se ambiciona. Es decir, una minoría específica y privilegiada de quienes no sorprende que, de todo el libro, se hayan quedado con aquella definición enérgica y evocadora del derecho a la ciudad, ya que está hecha a su justa media.

Lo que Harvey propone en Ciudades rebeldes es una representación esquemática de la realidad con el fin de llamar la atención hacia un problema concreto (los vínculos del sistema capitalista con los procesos urbanos), pero surge el riesgo de una interpretación al pie de la letra que termine actuando de base legitimadora para intereses supuestamente colectivos que en realidad tienen mucho de particulares. ¿Qué ocurre con aquellas personas sin capacidad alguna para «reinventar la ciudad de acuerdo a sus anhelos más profundos»? ¿Y con los colectivos desposeídos para los que «acceder a los recursos que la ciudad ofrece» es todavía algo lejos de saber a poco? Si no se resuelven las barreras que encuentran para participar en la vida urbana, las llamadas a la proactividad que constantemente lanzan los discursos actuales sobre la ciudad pueden tener el efecto de arrinconar sus necesidades aún más.

En Urbanismo para náufragos (2007), Pablo Gigosos y Manuel Saravia recuperan la idea del derecho a la ciudad desechándola rápidamente tras hacer una aproximación cautelosa. Los autores reconocen el éxito y el interés de la expresión, pero le ven un punto débil: «no da cuenta desagregadamente de los derechos puestos en juego». A partir de ahí, proponen un posicionamiento más claro: enfrentar a «la ciudad de las mayorías» un urbanismo para «el último ciudadano». Ese último individuo sería aquél que, ordenadas todas las personas en fila en función de su acceso a las oportunidades que ofrece la ciudad (uso del espacio, movilidad, participación, vida cultural, servicios 
públicos, etc.), aparecería siempre en las posiciones de cola. Contemplando la vida urbana desde la perspectiva de esas personas, sensibilizándonos y comprometiéndonos con la vulnerabilidad, podríamos aspirar a que nuestras ciudades fuesen más justas.

La infancia es uno de esos colectivos débiles a los que la ciudad no se lo pone nada fácil. Desgranaremos esa afirmación en los siguientes apartados, pero pensemos por ahora en la dependencia que niños y niñas sufren para moverse de un lugar a otro, en la pobreza de los espacios que reservamos para ellos, en la dificultad que tienen para reconocerse en un paisaje urbano del que parecen completamente borrados.

Como veremos, complicados factores culturales y sociales convergen en una situación que en el fondo tiene un carácter de lo más contradictorio. A lo largo del siglo pasado, la infancia ganó un peso social del que nunca antes había gozado: se elaboraron leyes que la reconocían como parte fundamental de la ciudadanía, se profundizó en cómo mejorar la atención que le dábamos, se desarrolló una sensibilidad comprometida contra su sufrimiento, se depositó en ella la confianza para la construcción de un mundo futuro... Y mientras todo esto ocurría, fuimos limitando más y más su libertad, construyendo hábitats insensibles e incluso contrarios a sus necesidades, encerrándola en casa a la espera de crecer. En algunos aspectos, las buenas voluntades parecen sanarnos la conciencia y darnos margen para a la infancia como un grupo en espera, subordinado a lo que decidamos los adultos.

Representaciones del conflicto social hay muchas. La que Harvey utiliza en la obra citada es la de «somos el 99\%» (ciudadanía contra élites extractivas), que podría situarse peligrosamente cerca de la de «la ciudad de las mayorías». En este texto, tomaremos la propuesta por Paul Thomson (citado en Ward, 1978), para quien la infancia «como muchos otros grupos marginados, ha luchado largamente contra su situación a través de la resistencia; en ocasiones abiertamente, otras de forma velada, existe una guerra contra los adultos equiparable en importancia a la guerra de clases o la de sexos».

Los siguientes apartados analizan cuatro imposiciones de los adultos que coartan el derecho a la ciudad de la infancia: restricción del uso del espacio urbano, vigilancia férrea excusada en la seguridad, aislamiento social durante el crecimiento y falta de participación en decisiones que le afectan. El quinto 
apartado cierra la reflexión reivindicando a la infancia como potencial elemento aglomerador del resto de colectivos que viven la ciudad en condiciones de desventaja no lo bastante reconocidas.

Antes de cerrar esta introducción, es bueno recuperar una palabras de Margaret Mead (citada en Ward, op. cit.), que nos recuerdan que «está bien pensar en el niño mientras recordemos que el niño no existe. Existen niños. Cada vez que los agrupamos en una misma categoría, perdemos algo». En el caso de la infancia, a las diferencias generacionales se superponen otras que necesitan una reflexión más profunda de la que se desarrolla en este artículo. Factores como pueden ser la estructura familiar y su nivel de renta, el género, la religión, la procedencia, la cultura o la edad introducen una diversidad de la que necesitamos ser conscientes. Una de las obras más inspiradoras en este sentido, de la cual se extraen las dos citas anteriores, es The Child in the City de Colin Ward (op. cit.), libro de mirada admirablemente amplia y empática que sentó las bases para los estudios en la dirección propuesta.

\section{El espacio de la infancia en la ciudad}

La ciudad es reflejo de la civilización que la construye y habita. Nos representa, evidencia el modo en que entendemos el mundo y cómo funcionamos como sociedad. La relación que establecemos con nuestro hábitat es bidireccional: lo hacemos a él y él nos hace. A medida que construimos la ciudad, depositamos significados en nuestro entorno de vida; éste, a su vez, es un potente transmisor de sentidos que moldean el modo en que entendemos el mundo. Partiendo de estas ideas, algo que debería preocuparnos es la pobre imagen que nuestras ciudades proyectan de la infancia y a la infancia. Coches que invaden la ciudad hasta su corazón, paisajes monótonos y faltos de escala humana, plazas sembradas de terrazas de bares pero en las que se prohíbe jugar, colegios tapiados con muros cada vez más altos y parques infantiles que parecen sacados de un catálogo de juguetes... ¿A qué se debe la ausencia de la infancia en el paisaje urbano? ¿Qué mundo ven niños y niñas a través de la ventanilla del coche?

Al observar la ciudad de hoy y hacernos preguntas de ese tipo, solemos responder con resignación, cuando no con simple naturalidad. Se es cons- 
ciente de que las ciudades han cambiado y de que, en ese cambio, niñas y niños han perdido posibilidades de las que gozaban no muy atrás. El recuerdo evoca cierta nostalgia, pero entendemos que la cosa no es más que una de tantas contrapartidas del progreso y que el desarrollo permite dar a nuestros hijos sustitutivos de alta calidad (dispositivos electrónicos, clases particulares, fines de semana en el centro comercial, etc.). Con esta excusa, nos deshacemos de la carga de tener que revisar nuestro entorno desde la perspectiva de la infancia.

Existe una pequeña publicación de 1982 titulada El niño y la ciudad. Constancia de un grito en la sorda vida urbana. En ella, Adriana Bisquert se detiene a escrutar el paisaje de Madrid, que era en aquel momento una ciudad a medio armar intentando iniciarse en la democracia. Con el abandono de los centros urbanos que marcó aquella época, destacaban en esa ciudad dos periferias: una infradotada e impuesta, la de los barrios pobres heredados del franquismo; y otra aseada, recién construida y elegida, donde una clase media en vías de formación buscaba en el coche y en la hipoteca la consolidación de su ascenso social. Para Bisquert, ambos espacios representaban una dramática «ruptura cultural» y reflejaban el «paso de una vida comunal a la familia nuclear y aislada, de la posesión de un espacio ambiental compartido y de su participación en él, a la posesión exclusiva del piso». La infancia era el grupo más perjudicado en aquel escenario, pues era desplazada por decisión de otros a ambientes sin contenido, sin posibilidades, que hacían imposible la vinculación afectiva y atrofiaban el desarrollo de la creatividad. A día de hoy, nuestras ciudades han resuelto parte de los déficits que sufrían en aquellos años y el paso de la vida ha pulido las asperezas de muchos barrios levantados en hormigón y ladrillo a cara vista. El paisaje antes descrito nos parecerá un recuerdo afortunadamente superado. Sin embargo, desde la perspectiva de la infancia, el problema incluso podría haberse agravado.

Según Bisquert, en el momento en que escribía, el principal mal que sufría la infancia era «el abandono». Las poderosas fotos que ilustran la publicación muestran a niños (principalmente ellos y no ellas) que deambulaban por las calles buscando qué hacer, jugaban con cualquier cosa que encontrasen, se reunían en grupos a la entrada de los portales, viajaban en metro ignorados por la gente, encontraban refugio en la libertad de los descampados y, ocasio- 
nalmente, se desfogaban contra el orden impuesto por los adultos por la vía del vandalismo. Vistas ahora, esas imágenes resultan chocantes. Son una de tantas cosas que han pasado a formar parte del pasado. Los niños y las niñas «abandonados» — es decir, fuera de la supervisión paterna - han desaparecido totalmente de nuestras calles.

La responsabilidad exclusiva de esa pérdida suele achacársele al coche. Sin lugar a dudas, los efectos del vehículo privado sobre nuestras ciudades han tenido un peso destacado y evidente en la reducción de la autonomía de la infancia y en su desaparición del paisaje urbano. Sin embargo, si miramos más allá del tráfico, veremos que el problema actual tiene una mayor profundidad. El grueso de la ciudad es poco sensible con la vida de la infancia, pero los llamados espacios infantiles no contribuyen a resolver esa situación sino que incluso le sirven de acicate. Los escasos lugares que reservamos a los niños y las niñas se han vuelto espacios confinados (diferenciados nítidamente del resto de la ciudad), especializados (diseñados para un uso único y ordenado), burocratizados (trabajados sin ninguna emoción), infantilizados (pensados con base en una visión reduccionista de la infancia) y estandarizados (producidos y comercializados en serie).

Desde principios del siglo xx hasta los años 70, tuvo lugar un debate de gran valor sobre la conveniencia o no de crear espacios específicos para la infancia. El diseño de zonas de juego fue el campo más fértil para esta reflexión (Friedberg, 1970). Las posturas a favor de construir espacios infantiles valoraban la liberación de la que gozaría la infancia en ese espacio que le era entregado para su propio disfrute; los de opinión contraria defendían que debía evitarse la reclusión en espacios específicos para promover que niños y niñas estuviesen en contacto directo con la vida de la ciudad. Actualmente, ese debate se ha desvirtuado y estancado por completo (Segovia, 2017), se tiende a la reclusión estricta de las criaturas y, por eso, no queda otra que posicionarse claramente a favor de la integración de la infancia en nuestras ciudades.

Francesco Tonucci, uno de los principales referentes contemporáneos en materia de ciudad e infancia, construye su discurso alrededor de la idea de devolver la ciudad a los más pequeños. Eso no significa aumentar la provisión de espacios para ellos, sino crear las condiciones necesarias para que vuelvan 
a pasear las calles con libertad. Nadie podría mostrarse en desacuerdo ante tan bondadoso propósito, pero Tonucci (2015) advierte de que la tarea no está exenta de tensiones y con ello recupera la idea de disputa entre infancia y adultos: «Si todos están de acuerdo, se puede suponer que creen que no es una opción arriesgada que pretende producir cambios radicales; que no se dan cuenta de que todo lo que deberemos restituir a los niños deberemos quitárselo a quienes hasta ahora lo han tenido como privilegio».

La tendencia a recluir a la infancia en lugares confinados bien podría estar relacionada con la problemática relación que mantienen con ella las personas adultas. Tonucci (2002) aporta otra sugerente reflexión al respecto: «El niño de hoy es preocupante, subversivo, revolucionario, porque es diferente de nosotros, los adultos: piensa de otra manera; ve las cosas de otra manera que no es errada sino sólo diferente; vive sentimientos profundos, explosivos; tiene necesidades a menudo en conflicto con las nuestras. Tener en cuenta sus exigencias y sus ideas puede comportar profundas adaptaciones y renuncias en los adultos».

Detrás de la falta de integración de las niñas y los niños en el entorno urbano, se halla una comprensión de la infancia como etapa previa a su ingreso en la sociedad. La emotiva expresión «los niños son la ciudadanía del futuro» implícitamente soslaya su condición de ciudadanía presente. Mientras se forman, niños y niñas no son todavía parte reconocida y, en consecuencia, que su vida se desarrolle al margen de la ciudad se vuelve permisible. Bajo la luz de estas ideas, la expulsión de la infancia de las calles y la creciente ordenación de sus hábitos y de su uso del espacio, encontraría una de sus principales motivaciones en cierta falta de valentía por parte de los adultos para confrontar su punto de vista con el de la niñez.

\section{Autonomía por seguridad y los porqués de la sobreprotección}

Desde los años 70, la distancia permitida a niños y niñas para el juego autónomo se ha reducido un $90 \%$ y su tiempo libre cuenta unas 15 horas menos a la semana (DGT, 2013). En aquella época, prácticamente todos los niños de once años acudían al colegio sin ir acompañados, en los 90 lo hacía en $50 \%$ y una década más tarde el porcentaje rondaba el 25\% (Román y Salís, 
2010). Datos de este tipo reflejan la progresiva pérdida de libertad que sufre la infancia y la desposesión del espacio público que tratábamos en el apartado anterior. Esta limitación de la autonomía se relaciona antes con la percepción de los adultos que con la falta de capacidades reales de las niñas y los niños. Siguiendo esa línea, una observación realizada por Simon Kuper (2016) introduce un nuevo asunto en nuestra reflexión: hasta 1985, la palabra «libertad» aparecía más veces en los textos sobre la infancia que la palabra «seguridad»; a partir de aquel año, la relación se invirtió y la palabra «seguridad» fue ganando más y más presencia. Existe una relación dialéctica entre la seguridad y la libertad; el aumento de una suele exigir cierta renuncia de la otra. ¿Por qué los adultos hemos decidido poner la seguridad de los niños y las niñas por encima de su libertad?

La preocupación por la seguridad cuando pensamos en la infancia juega un papel importante en su pérdida de acceso al espacio de la ciudad. Echando mano de nuestra experiencia con Pas a Pas, en las primeras fases de trabajo vimos que las propuestas para mejorar la calle se centraban en la protección frente al coche (instalación de badenes, bolardos, vallas frente a las puertas de los colegios, señalización vial...). En aquel momento decidimos dejar de usar la expresión «rutas seguras», habitual en las iniciativas de caminos escolares, pero nunca hemos logrado que los medios de comunicación dejen de emplearla con insistencia para describir el proyecto. Al hablar de «rutas infantiles seguras», de algún modo legitimábamos que el resto de la ciudad pudiese permitirse no ser segura para la infancia. Trazando itinerarios adecuados para ella, le asignábamos un espacio específico y, por extensión, la ciudad más allá de esa línea le pertenecía un poco menos. Ésa era la trampa de la seguridad.

Al convertir la seguridad en una prioridad exclusiva, hemos olvidado que el riesgo es un componente necesario para el desarrollo personal. El proceso de hacer frente a un obstáculo, explorar las posibilidades para abordarlo, sopesar las propias habilidades y aprender a dominarlo, traza un camino de aprendizaje imprescindible. Solemos infravalorar la capacidad de los niños y las niñas para llevar a cabo ese proceso. Realmente, es la falta de hábito a la hora de desenvolverse por cuenta propia lo que resulta en cierta incapacita- 
ción. Por ejemplo, «la falta de familiaridad con el tráfico y sus peligros puede ser tan letal como la constante exposición a él» (Ward, op. cit.).

Multitud de padres y madres, particularmente aquellos con más renta y formación, admiten que someten a sus hijos a una protección excesiva, pero dicen sentirse incapaces de remediarlo (Rosin, 2014). ¿En qué radica esta actitud? Marta Román y Begoña Pernás (2009) explican el problema de la sobreprotección a partir del desarrollo del estado del bienestar, a lo largo del cual se habrían concatenado tres factores. En primer lugar, la infancia pasó de tener un «valor instrumental» a tener un «valor expresivo». Lo que antes era un elemento que ayudaba a la economía familiar se convirtió en un gasto económico que reporta un enorme beneficio emocional. En segundo lugar, la estructura demográfica se alteró, las familias empezaron a tener menos descendencia y la infancia, al convertirse en un segmento más escaso de la sociedad, ganó aún más aprecio. En tercer lugar, llegados a nuestros días, la vida adulta se vuelve cada vez más inestable y en el vínculo con los hijos y las hijas se quiere encontrar un espacio que nos proteja de la inseguridad, de ahí una mayor preocupación por evitar que nada dañe nuestro último refugio. El planteamiento de las autoras es interesante, pues le da la vuelta por completo al enfoque habitual. Estando acostumbrados a dar por sentado que los niños y las niñas son dependientes de los adultos, se descubre la posibilidad de que exista una dependencia inversa incluso mayor.

Otra cita de Tonucci (op. cit.) sirve de perfecto cierre a este bloque: «La primera característica de un buen padre debería ser volverse cada día menos necesario para su propio hijo». Estas palabras nos ofrecen una perspectiva sobre la crianza radicalmente opuesta a la sobreprotección.

\section{De la casa al cole, el crecimiento apartado de la vida pública}

Como vamos viendo, la reducción del derecho de la infancia a la ciudad está vinculada no sólo a la transformación del entorno urbano sino también a cambios sociales y culturales (si es que ambas cosas pudieran separarse).

El origen del problema que tratamos podría rastrearse aún más atrás, pero suele señalarse a los periodos de posguerra como el momento clave a partir 
del cual comienza a extenderse una ideología que, frente a las hostilidades del ámbito público, ensalza la armonía del hogar y la virtud de la vida en familia (Booth, Darke y Yeandle, 1988). A los niños y las niñas, lógicamente, les corresponde estar en el refugio seguro del espacio privado y no expuestos a la degeneración de lo público. Todavía hoy, la etiqueta «niños de la calle» sigue resultándonos familiar y nos transmite resonancias negativas.

Extensión de lo anterior, Román y Pernas (op. cit.) explican cómo encerrar a la infancia en casa resultó en una maternidad privatizada e intensiva. Desde aquel momento, todo lo que tiene que ver con los niños y las niñas debe resolverse en el ámbito doméstico, resultando en un incremento de responsabilidades en la esfera privada al que tuvieron que hacer frente principalmente las mujeres. Esa responsabilidad no hace referencia sólo a una mayor carga de trabajo, sino también a una mayor responsabilidad de cara a la sociedad. Y es que cualquier problema que afecte a la infancia tiende a asociarse a una mala crianza (por ejemplo, la obesidad infantil suele tratarse antes desde los malos hábitos de alimentación - de la que suelen ocuparse las madres - que desde la perspectiva de la vida pasiva que nuestra sociedad impone a las criaturas).

El incremento de las atenciones a la infancia también provocó que todo lo que gira alrededor de ella se fuese convirtiendo en asunto de estudio especializado y se ordenase en diferentes campos disciplinares. En concreto, la educación empezó a entenderse como una actividad enmarcada exclusivamente en el ámbito escolar. Esto resultó en un incremento de las responsabilidades de los centros de enseñanza similar a la que recayó sobre los hogares. Cuando hoy nos acercamos a los colegios con un proyecto externo, y aquí la experiencia de Pas a Pas vuelve a servir de ejemplo, es fácil percibir que éstos están completamente saturados de trabajo, pues a través de ellos se intenta vehicular todo lo que tiene que ver con los pequeños (proyectos municipales, campañas de todo tipo, celebración de festividades, etc.).

Es habitual pedir a los colegios que se abran a sus ciudades y a sus barrios. De hecho, sería deseable que esto ocurriese porque de esta forma el proyecto educativo se enriquecería. Que niños y niñas conozcan el entorno donde viven, su barrio, su historia y sus gentes es un requisito fundamental para que desarrollen valores como el apego al lugar, el sentido crítico o la iniciativa 
para la participación. Aún así, es necesario tener en consideración la sobrecarga que los colegios sufren antes de plantearles nuevas exigencias y, sobre todo, es necesario preguntarse si esa apertura es responsabilidad exclusiva de los centros.

El retraimiento de la crianza al interior del hogar y la concentración de la educación en el interior de las escuelas produjeron una consecuencia adicional en la vida pública: el debilitamiento del sentimiento de responsabilidad comunitaria alrededor de la infancia y, con ello, la erosión de uno de los principales pilares de la solidaridad social. Desde ese momento, empezó a desplegarse el discurso de la desconfianza y el miedo al extraño, uno de los factores que provocan mayor recelo entre padres y madres cuando se les habla de relajar la supervisión sobre sus hijos e hijas.

La desinhibición de la responsabilidad social alrededor de la infancia es un problema central a trabajar, sólo así se corregirá el exceso de carga sobre los hogares y los centros de enseñanza. La educación debe empezar a concebirse como un proceso, no segregado y de responsabilidades pulcramente delimitadas, sino abierto y colectivo. No es casual que Jane Jacobs (2011) introdujese el asunto de la reconstrucción del apoyo comunitario en un capítulo de Muerte y vida de las grandes ciudades titulado «Uso de las aceras: incorporación de los niños». En ese capítulo, se explica que la cohesión del vecindario garantiza la seguridad y la convivencia mejor que la mentalidad proteccionista y policial; y se demanda como «principio más fundamental de una buena vida urbana: todo el mundo ha de aceptar un canon de responsabilidad pública mínima y recíproca, aún en el caso de que nada en principio les una».

Con Pas a Pas hemos descubierto que los colegios son un valioso punto de apoyo para emprender esta reconstrucción, pero no tanto por lo que ocurre dentro de ellos como por lo que los rodea. En torno a los colegios se organiza una valiosa comunidad de actores: madres y padres, las AMPA, el profesorado, la policía local, el comercio cercano... Fomentar su implicación y la acción conjunta es un asunto a encarar desde la política pública que contribuye a ampliar la concepción social de la educación, a avanzar hacia la solidaridad comunitaria y a mejorar las relaciones de convivencia. 


\section{La delicada aproximación a la participación infantil}

El reconocimiento de la plena ciudadanía de la infancia desde su nacimiento, recogido en la Convención de los Derechos del Niño aprobada por las Naciones Unidas en 1989 (texto de importancia central por su vocación universal), incluye el derecho de las niñas y los niños a participar en la vida en comunidad y decidir sobre los temas que les afectaban.

Las iniciativas que abren el debate urbano a la participación de la infancia tienen cierto recorrido histórico y actualmente parecen generar un interés creciente. A priori, debemos diferenciar entre dos tipos de experiencias en función de sus tiempos: las que se plantean como actividades puntuales, la mayoría de las veces organizadas «de arriba hacia abajo» por la administración; y las que aspiran a tener una cierta continuidad, para lo cual se necesitan refuerzos y trabajar cierta horizontalidad. Ambas son efectivas para dar visibilidad a la infancia en el debate público, pero las primeras corren mayor riesgo de caer en un uso instrumental de la figura de los niños y las niñas, siendo más frecuentes de lo que sería deseable los proyectos que se conforman con obtener cierto éxito mediático sin producir cambios efectivos. Por otro lado, como estamos viendo, los cambios que se ambicionan son profundos y necesitan un trabajo insistente y sostenido. En nuestra experiencia con Pas a Pas, trabajar en un contexto participativo de larga duración es una de las cosas que nos hacen sentir más afortunados. Pensamos que, de otro modo, la tarea aún en marcha de dar consistencia al proyecto sería imposible.

Adriana Bisquert (op. cit.) también aborda el tema de la participación infantil y lanza un juicio lapidario al respecto. Dice en primer lugar que «se manipula y se explota su imagen (la de la infancia) de modo sentimentaloide y peyorativo»; y algo más adelante nos pregunta: «¿no es acaso esa participación una forma más de manipular la figura del niño con vistas a una imagen burlesca de la sociedad participativa?». Al profundizar en ambas citas, encontramos dos puntos de interés para continuar nuestra reflexión.

La primera de ellas nos llama a pensar en el imaginario colectivo que construimos alrededor de la infancia. Una vez más, los adultos detentan el poder sobre esa construcción, a la que se da forma a través de la nostalgia de las libertades perdidas al caminar hacia la vida adulta y del recuerdo idea- 
lizado de la propia infancia. Esa imagen, estando más relacionada con las proyecciones adultas que con la realidad de los niños y las niñas, termina actuando como un corsé sobre ellos. A finales de los 70, Colin Ward escribía que el niño — que, como ocurre ahora, ocupaba la imagen pública de la época por encima de la niña - estaba obligado a «ser amable, sincero, no estar nunca triste, ser siempre singular, tener un carácter fuerte, saber cuándo enfrentarse a la autoridad». No ajustarse a esa descripción, lo empujaría a sentirse rechazado y frustrado. En nuestros días, el imaginario alrededor de la infancia probablemente se haya empobrecido todavía más, y está marcado por la infantilización. Ésta no es más que un esquema ultra-simplificado con el que los adultos reducimos la complejidad de la niñez, lo cual nos vuelve a servir para librarnos de un ejercicio comprometido a costa de imponer a la infancia una imagen que restringe su posibilidad de conocerse a sí misma.

La segunda cita de Bisquert sirve para llamar la atención sobre el hecho de que la participación que proponemos a la infancia se enfoca habitualmente hacia la disciplina y el civismo. En nuestras llamadas a la participación, solemos ofrecerles metodologías que los incitan a que aprendan a formular opiniones, a que experimenten con sistemas de trabajo propios de los adultos, a que debatan entre ellos y se inicien en la democracia, a que se vuelvan más responsables... Todas estas intenciones son loables y, probablemente, positivas para el desarrollo individual de las criaturas, pero dejan el regusto de estar orientadas a un único objetivo: hacer que sean un poco más parecidas a como nos gustaría que fuesen.

Esto último se relaciona con una tendencia analizada por Annette Lareau (citada en Rosin, op. cit.) que señala cómo, hoy en día, los padres y las madres buscan tan activamente el enriquecimiento de sus hijos e hijas que terminan convirtiéndolos en proyectos personales. Como páginas en blanco en las que van escribiendo contenidos, el crecimiento se imagina como un desarrollo lineal, controlado e incremental. Según Lareau, esta manera de actuar se vincula principalmente a las parejas de clase media-alta. Las clases trabajadoras y las familias pobres no observan a sus pequeños tan de cerca, sino que dejan más espacio a sus logros a partir de una comprensión más natural del crecimiento. La primera forma de crianza tiende a considerarse superior a la segunda, pero únicamente garantiza una mejor preparación para la forma 
de vida típica de la clase media, inculcando tanto sus entusiasmos como sus frustraciones en la descendencia.

Como alternativa a esa participación orientada al civismo, Paul Goodman (1960) planteó un enfoque subversivo y proclamó que hay dos cosas que la infancia y la juventud aportan a nuestra sociedad: «capacidad y sabotaje». La capacidad se orientaría a dar continuidad y mejorar lo que las generaciones precedentes construyeron, mientras que el sabotaje serviría para hacer saltar por los aires ese orden previo cuando las cosas se volviesen demasiado burocráticas, herméticas y pesadas. Tonucci (op. cit.) apunta en una dirección similar cuando dice que los niños y las niñas son buenos agentes para rebelarse contra las injusticias de la ciudad, porque no están corrompidos por ellas ni acostumbrados a darlas por sentado.

Ciertamente, parece saludable que la participación infantil se plantee en clave ligeramente rebelde, dado que, como venimos diciendo, existe un enfrentamiento entre niños y adultos que sólo puede resolverse en igualdad de condiciones a través del choque. Dar a la infancia posibilidades para la participación significa dejarla hacer por ella misma y eso pasa por adoptar una actitud más titubeante como adultos. Es decir, por ceder poder.

Sintetizando todo lo expuesto hasta ahora, la lucha por el derecho de la infancia a la ciudad se orienta a permitirles tomar partido en la vida urbana y en la comunidad. Esto exige dar a la infancia espacio, no sólo físico, sino también social.

\section{La infancia como vía hacia la inclusividad}

La reflexión que hemos propuesto se ha construido sobre la base de que existe una situación de conflicto entre la infancia y el mundo adulto. Como hemos visto, a consecuencia del marcado desequilibrio de fuerzas, el desenlace de la disputa tiende a ser en perjuicio de la parte más débil. Quizá se haya notado que, a lo largo de la redacción, se ha procurado usar el lenguaje inclusivo cuando se hacía referencia a los niños y las niñas, pero no se ha hecho lo mismo al hablar de los adultos. Esto último ha sido intencionado y no un desliz. 
Durante décadas, múltiples urbanistas han llamado la atención sobre el hecho de que nuestras ciudades han sido tradicionalmente pensadas para la comodidad de un tipo muy concreto de individuo: el hombre blanco en edad productiva, cabeza de familia, propietario de una vivienda y un coche, con trabajo y cierta seguridad de ingresos, descargado de la tarea de los cuidados por su mujer.

Es por ejemplo muy gráfico el modo en que se elabora un Plan General de Ordenación Urbana. Se empieza por la «planificación estructurante», dibujando la ciudad en su conjunto, trazando ejes viarios y separando zonas de actividad, trabajando en una escala que sólo puede aprehenderla quien tiene vehículo propio. Una vez aprobado lo anterior, se pasa a la "ordenación pormenorizada", que consecuentemente tiene un carácter subordinado. En este segundo paso, se atiende al espacio de proximidad utilizando criterios estadísticos que tampoco garantizan un entorno urbano accesible o de calidad.

Aunque tienda a pensarse que el modelo del hombre adulto tiene una representatividad mayoritaria en nuestra sociedad, en absoluto es así. Las mujeres cargan con los asuntos relacionados con los cuidados más que él, la juventud no puede acceder a ciertas facilidades por motivos de renta y él sí puede permitírselo, llega un momento en el que la gente mayor no puede conducir pero para él eso todavía queda lejos... Por cada factor que aleja a cualquier persona del canon del hombre adulto, y existen muchos otros además de los que hemos usado como ejemplos, se suma una barrera para la participación en la vida en la ciudad.

Así pues, el conflicto generacional que existe entre la infancia y el adulto también se refleja en el conflicto que mantienen muchos otros grupos con aquel «hombre ideal». Las mujeres, la juventud, la gente mayor, las personas de origen extranjero, las que viven en situación de pobreza, las discapacitadas, las discriminadas por motivos religiosos y culturales... Todas ellas son también «últimos ciudadanos» a los que la ciudad concebida para la comodidad del adulto productivo sitúa en una posición de desventaja. Desde las políticas públicas debe tomarse conciencia de que todos éstos no son «grupos especiales» con «necesidades especiales», a los que por tanto se atiende de manera sectorializada y asistencialista; sino que forman un conjunto diverso 
pero interrelacionado, que además aspira a posicionarse como un espacio clave para repensar nuestra ciudad y sus horizontes.

Una infancia activa y valorada socialmente (integrada en la vida urbana, segura de sí misma, arropada por el compromiso comunitario y que mantenga activo nuestro sentido crítico) es un estupendo elemento aglomerador para unir y dar voz a esos otros grupos generalmente excluidos del debate urbano. Para ilustrar las posibilidades de esta afirmación y no quedarnos en lo proclamativo, nos sirve como ejemplo el reconocimiento de Pas a Pas en la «I Edición de los Premios Vivienda, Movilidad y Urbanismo con Perspectiva de Género» de la Generalitat Valenciana, otorgado por el vínculo que el proyecto ha trabado con las mujeres.

A mediados del segundo curso del proyecto, se puso en marcha el Pedibús de Pas a Pas, una iniciativa que consiste en acudir al cole paseando y en compañía todos los viernes. La organización del Pedibús está apoyada por la administración, los colegios, la policía y el comercio local; pero el papel fundamental lo asume un grupo de personas que, de forma voluntaria, se encargan semanalmente de recoger a los niños y las niñas en el lugar y hora acordados y acompañarlos al cole. Este grupo de aproximadamente 25 personas ha resultado estar compuesto de manera casi exclusiva por madres (sólo dos padres completan el grupo). El Pedibús de Pas a Pas se ha convertido así en un espacio femenino de organización colectiva, de apoyo mutuo alrededor de la infancia y de visibilización de cómo las tareas relacionadas con el cuidado siguen recayendo de manera mayoritaria sobre los hombros de las mujeres. La memoria completa presentada a la convocatoria, que incluye una revisión del Pedibús desde la perspectiva de las madres voluntarias, se puede descargar de la página web de Pas a Pas. Éste es el tipo de alianzas inesperadas a las que una política pública centrada en la infancia debería aspirar.

Dice Tonucci que una ciudad buena para los niños — para cualquiera de los grupos antes enumerados - es una ciudad buena para la mayoría de las personas. Pero a eso cabría añadir que una ciudad buena para la mayoría no es necesariamente una ciudad buena para quienes viven en situación de desventaja por motivos de renta, edad, género o procedencia. Al tomar conciencia de esto, se descubre que la ambición última que debe inspirar la observación 
del entorno habitado desde los ojos de la infancia es contribuir a que nuestras ciudades sean más humanas, inclusivas y justas.

\section{Referencias}

Bisquert, A. (1982). El niño y la ciudad. Constancia de un grito en la sorda vida urbana. Madrid: Servicio de Publicaciones del Colegio Oficial de Arquitectos de Madrid.

Booth, C., Darke, J. y Yeandle, S. (coord.) (1988). La vida de las mujeres en las ciudades. La ciudad, un espacio para el cambio. Madrid: Narcea.

DGt (2013). Camino escolar paso a paso. Madrid: Ministerio del Interior.

Friedberg, P. (1970). Play and interplay. London: The Macmillan Company.

Gigosos, P. y SARavia, M. (2010). Urbanismo para náufragos. Lanzarote: Fundación César Manrique.

Goodman, P. (1960). Growing up absurd. New York: Vintage Books.

Harvey, D. (2012). Rebel Cities. From the right to the city to the urban revolution. London: Verso Books.

JACOBS. J. (2011). Muerte y vida de las grandes ciudades. Madrid: Capitán Swing.

KuPER, S. (2016). «Safety first. the new parenting». Finantial Times.

Lefebvre, H. (1969). El derecho a la ciudad. Madrid: Península.

Román, M. y Pernás, B. (2009). ;Hagan sitio, por favor! La reintroducción de la infancia en la ciudad. Madrid: Organismo Autónomo Parques Nacionales.

- SAlís, I. (2010). Camino escolar. Pasos hacia la autonomía infantil. Madrid: Ministerio de Fomento.

Rosin, H. (2014). «The overprotected kid». The Atlantic.

Segovia, CH. (2017). «Parques infantiles diseñados por catálogo». eldiario.es.

Tonuccı, F. (2002). Cuando los niños dicen jbasta! Madrid: Fundación Germán Sánchez Ruipérez.

- (2015). La ciudad de los niños. Barcelona: Graó.

W ARD, C. (1978). The child in the city. London: The Architectural Press Ltd. 
